\title{
GCU
}

Glasgow Caledonian

University

University for the Common Good

\section{A less-intrusive approach to stabilize VSC transmission against highly variable grid strength}

Zhang, Z. ; Chen, D.; Givaki, K.; Xu, L.

Published in:

IEEE Journal of Emerging and Selected Topics in Power Electronics

DOI:

10.1109/JESTPE.2020.3030362

Publication date:

2020

Document Version

Author accepted manuscript

Link to publication in ResearchOnline

Citation for published version (Harvard):

Zhang, Z, Chen, D, Givaki, K \& Xu, L 2020, 'A less-intrusive approach to stabilize VSC transmission against highly variable grid strength', IEEE Journal of Emerging and Selected Topics in Power Electronics, vol. 9, no. 6, pp. 7199-7211. https://doi.org/10.1109/JESTPE.2020.3030362

\section{General rights}

Copyright and moral rights for the publications made accessible in the public portal are retained by the authors and/or other copyright owners and it is a condition of accessing publications that users recognise and abide by the legal requirements associated with these rights.

Take down policy

If you believe that this document breaches copyright please view our takedown policy at https://edshare.gcu.ac.uk/id/eprint/5179 for details

of how to contact us. 


\title{
A Less-Intrusive Approach to Stabilize VSC Transmission against Highly Variable Grid Strength
}

\author{
Z. Zhang, D. Chen, Senior Member, IEEE, K. Givaki, Member, IEEE and L. Xu, Senior Member, IEEE
}

\begin{abstract}
A less-intrusive solution to stabilize a Voltage Source Converter (VSC) over an unknown grid strength is presented in this paper. The existence of equilibrium point is investigated as a pre-requisite to stabilization. By partially imposing grid forming control, a simple auxiliary outer loop is proposed to exhaust the physical limit of power delivery in steady state and provide support to fault-ride-through operations over a wide range of grid strength. The proposed control can be used to upgrade a commissioned VSC with inner current loop intact and overcome the impact of negative voltage sensitivity; it also offers a robust non-intrusive solution to stabilize VSCs externally. The effectiveness of the proposed schemes are verified by analysis in frequency domain and simulations in Electromagnetic Transient (EMT) time domain considering change of grid strength and fault-ride-through.
\end{abstract}

Index Terms - voltage source converter, weak grids, voltage stability, voltage sensitivity, stabilization, damping, fault-ridethrough.

\section{INTRODUCTION}

Indexed by Short Circuit Ratio (SCR), the grid strength of a power network can be variable, which can impact the integration of a Voltage Source Converter (VSC) [1]. The variation can be caused by fast-developing incidents, such as depletion of a hydro power plant, isolation of a faulty power line, network operations, etc., which are usually temporary [2]. On the other hand, the change of SCR values can also be caused by a slowly-evolving process such as replacement of centralized synchronous generators with renewables, which is ever-lasting and already witnessed by Great Britain power network [1]. For both scenarios, the variation can be significant [2]. One seldom-explored issue is whether those commissioned VSCs can sustain with such variations that they were not designed for. Obviously, a robust solution against the variation of grid strength is expected for those VSCs, either implemented by VSC vendors or utilities.

The control strategies of a VSC can be divided into 2 types inner loop for voltage regulation [3-5] and inner loop for current regulation [6-8].

By mimicking the behavior of synchronous machines, control strategies using inner voltage loop, which are often referred to as Virtual Synchronous Machine (VSM) [3] or equivalently power synchronization control [4][5], can offer stability in weak grids [4][5], as well as strong grid [3]. However, they are limited by the difficulties in handling transient current, which requires a mode switching to ride through a fault [9].

Typically using current feedback control for the inner loops, classical vector control offers capability in handling transient current as well as steady-state, and is implemented in most commissioned VSC projects [10]. A well-recognized challenge for classical vector control is the risk of instability in weak grids [10]. This is a result of its original design assumption, which presumes that the grid strength is always adequate, and the VSC's impact to the grid is negligible [6]. Such assumption has been proved invalid for weak grid conditions due to two amplified issues, i.e. small-signal damping [11-14] and the constraint of power flow [15][16].

Since PLL was regarded as the cause of negative damping in weak grids [17-18], intensive researches have been carried out to mitigate the impact brought by PLL [19-23]. The corresponding approaches can be categorized into two types: 1) tuning the parameters of a PLL [22][23]; 2) modifying the structure of PLL [19][20]. By reducing the gains of a PLL in weaker grids, the former type can effectively improve system damping when the grid condition is fixed or known; however, its robustness is undermined with unknown grid strength, especially during a fast-developing event, e.g. fault isolation. By adding extra compensation or modifying the closed-loop design of a PLL [19][20], the latter approach can be designed with better damping against SCR variations. However, the absence of effective reactive power dispatching and voltage control scheme limits the operational margin [21]. Known as "var/volt" droop, reactive power/voltage droop can provide automatic voltage support [22]; nevertheless, its coupling effect with electromagnetic damping has been overlooked and therefore not adequately investigated. Further, for most studies reported, stability analysis is based on a presumed equilibrium point [3-21], but how it is reached has not been explicitly explained.

Recognizing PLL not the sole disturbing element for vector control in weak grids, another category of control approaches introduce outer loops to mitigate instability of vector control [24-26]. Compensating reactive current according to active current, an active power based feedforward process can provide appropriate reactive power; at the meantime, it also improves damping in extremely weak grids. Nevertheless, this scheme requires instantaneous information of grid impedance, which is demanding in case of a significant grid change [24]. As an alternative solution, cross-coupling control is effective in addressing the issues of damping and reactive power at the same time, but its effectiveness is sensitive to variations of operational points and grid conditions. As a result, it is subject to dedicated design of gain scheduling scheme, which is of high complexity when grid strength is highly variable [25].

Moreover, for both PLL and outer loop approaches reported, the access to the internal control of the main VSC is essential [17-26]. In reality, it is inconvenient for the owners 
to upgrade those commissioned VSCs due to legal disputes and access difficulties.

As a non-intrusive solution, battery storage/STATCOM has been suggested to provide damping service for wind farms with VSM control [27]. With the challenge of handling transient current inherited from VSM, such external stabilizer requires extra current rating to ride through a fault, which would add up to the capital cost significantly.

Another type of VSC control cascades inner loops of current with deterministic outer loops, i.e. voltage/frequency droops [28][29]. By applying closed-loop controls over the full vector of terminal voltage, such control scheme is desirable for island mode as a grid-forming scheme [33]. When the grid strength is significantly variable, a trade-off between the accuracy of power dispatching and coordination among voltage sources is expected. Thus, complex parametric tuning or mode switching will be again expected according to instantaneous grid condition. Practically, it is rarely implemented by VSCs of large scale.

In this paper, a simple approach of partial grid-forming is proposed. By analysing equilibrium region of VSC operation, selected voltage loops are proposed given the constraint of power flow and electromagnetic dynamics. Comparing with known approaches, the proposed scheme can provide an improved performance with the following benefits altogether: (1) robustness against unknown grid strength over a wide range (from $\mathrm{SCR}=0.9 \sim \infty$ ) including the region of $\mathrm{d} Q / \mathrm{d} V<0$; (2) flexibility as a less- or non-intrusive solution to commissioned VSCs; (3) improvement of transient stability during a Fault-Ride-Through (FRT) under extremely weak grid conditions; (4) The mechanism of instability in weak grid is also updated other than the known issue of PLL.

The rest of this paper is organized as follows. The system benchmark model, static operational constraints of power flow is introduced in Section II; the principles, dynamic analysis and time domain case studies of the proposed control scheme are presented in Section III; the non-intrusive stabilization schemes and case studies are introduced in Section IV, and the conclusion is finally drawn in Section V.

\section{Steady State Constraints And EQuilibrium Point}

\section{A. System layout and cascaded control for VSC}

In order to analyze the performance of a vector control based VSC in weak grids, a benchmark system is established in Fig. 1 as shown, where the classical average converter model is used in this paper [20-28].

Illustrated by the main circuit in Fig. $1, R_{l}$ and $L_{l}$ are the resistance and inductance of the VSC reactor; $C$ the VSC filter capacitance; $R_{T}, L_{T}$ the grid transformer resistance and leakage inductance; $R_{N e t}$ and $L_{N e t}$ the equivalent resistance and inductance of the AC grid; $V_{C}$ and $V_{\text {conv }}$ the magnitudes of the capacitor voltage and the modulated voltage of the VSC bridge ; $R_{2}$ and $L_{2}$ the equivalent total converter side impedance of the grid and transformer; $p_{1}$ and $q_{1}$ the active and reactive power of VSC flowing towards grid side; $p_{2}$ and $q_{2}$ the active and capacitive reactive power flowing into the grid; $q_{\mathrm{c}}$ the capacitor reactive power flowing into the grid; $\overrightarrow{\boldsymbol{I}_{2}}$ the grid current vector.
The classical vector control of VSC in d-q reference frame is also incorporated in Fig. 1, where instantaneous values are considered: $V_{\mathrm{Cd}}$ and $V_{\mathrm{Cq}}$ refer to the capacitor voltage components in d- and q- axis; $i_{\mathrm{Cd}}$ and $i_{\mathrm{Cq}}$ the VSC current components in d- and q-axis; $i_{\mathrm{Cd}}{ }^{*}$ and $i_{\mathrm{Cq}}{ }^{*}$ the reference values of $i_{\mathrm{Cd}}$ and $i_{\mathrm{Cq}} ; V_{\mathrm{Convd}}{ }^{*}$ and $V_{\mathrm{Convq}}{ }^{*}$ the modulated voltage order of VSC in d- and q- axis; $V_{\mathrm{c}}{ }^{*}$ and $p^{*}$ are the references of capacitor voltage the active power; $V_{\mathrm{cd}}{ }^{*}$ and $V_{\mathrm{cq}}{ }^{*}$ are the references of outer voltage control loops; are the dispatched active and reactive power respectively. Ignoring the modulation harmonics, the average model is used in the time domain simulation of this paper.

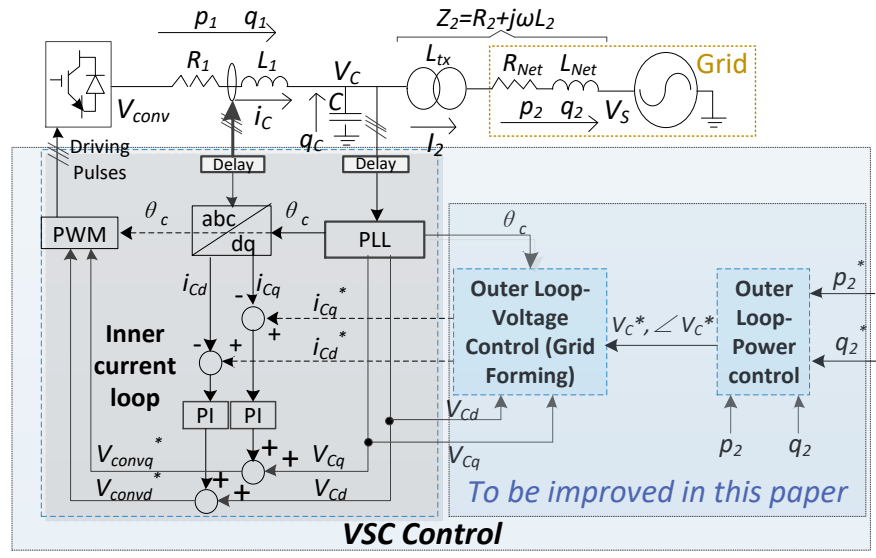

Fig. 1. Generic benchmark VSC model with cascaded grid forming control.

To preserve the capability of FRT, inner current loops are essential. Despite various implementations and adopted reference frame, the control structure of a cascaded VSC control can be generalized as Fig. 1 shows [28][29][33]. With the closed-loops of a complete voltage vector feeding inner loops, the VSC terminal can operate as an ideal slack bus with improved damping and robustness against grid conditions [30]. However, when a VSC is to operate as a non-slack bus, further outer power loops have to be cascaded [33].

The provision of order for a complete voltage vector requires the references of active power and reactive power simultaneously. When the grid strength is unknown, the reactive power compensation is sensitive to grid conditions and the mitigation will involve further loops. This will lead to a very complex control design with quite a few cascading loops. Therefore, a simpler outer-loop control strategy is proposed in this paper for VSCs operating as a non-slack bus.

\section{B. The Non-equilibrium region and static voltage sensitivity}

This section investigates how power dispatching will affect the existence of equilibrium point over variable grid strength.

From Fig. 1 and using the grid voltage as the reference vector, there is [24]

$$
\begin{gathered}
-1 \leq\left(P_{2} \omega L_{2}-Q_{2} R_{2}\right) /\left(V_{C} V_{S}\right)=\sin \theta_{C} \leq 1 \\
-1 \leq\left(V_{C}^{2}-Q_{2} \omega L_{2}-P_{2} R_{2}\right) /\left(V_{C} V_{S}\right)=\cos \theta_{C} \leq 1
\end{gathered}
$$

where $P_{2}$ and $Q_{2}$ are the phasor average form of $p_{2}$ and $q_{2}$, respectively. By applying $(1)^{2}+(2)^{2}$ on both sides of the equal sign, (1)(2) will lead to

$$
\left(P_{2} \omega L_{2}-Q_{2} R_{2}\right)^{2}+\left(V_{C}^{2}-Q_{2} \omega L_{2}-P_{2} R_{2}\right)^{2}=\left(V_{C} V_{S}\right)^{2}
$$


To ensure the existence of a real solution of the equilibrium voltage $V_{\mathrm{c}}$ to $(1)(2)$, there is [16][24]

$\Delta=\left(2 P_{2} R_{2}+2 \omega L_{2} Q_{2}+V_{S}^{2}\right)^{2}-4\left[\left(-R_{2} Q_{2}+\omega L_{2} P_{2}\right)^{2}+\right.$

$\left.\left(P_{2} R_{2}+\omega L_{2} Q_{2}\right)^{2}\right] \geq 0$

Solving (4) for $Q_{2}$, there is

$$
Q_{2} \geq \frac{-V_{S}^{4}-4 Q_{2} R_{2} V_{S}^{2}+4 R_{2}^{2} Q_{2}^{2}+4 \omega^{2} L_{2}^{2} P_{2}^{2}}{4 \omega L_{2} V_{S}^{2}+8 P_{2} R_{2} \omega L_{2}}
$$

The inequities of (1)(2)(4) are sufficient and necessary condition to ensure existence of equilibrium point. Assuming $R_{2}<\omega L_{2}$ for transmission network, there is $\omega L_{2} \approx 1 / S C R$, and $p_{1}=p_{2}$, (4) can be re-organized as

$$
Q_{2}\left(P_{1}, S C R\right) \geq \frac{\left(-V_{S}^{4}-4 P_{1} R_{2} V_{S}^{2}+4 P_{1}^{2} / S C R^{2}+4 Q_{2}^{2} R_{2}^{2}\right) S C R}{4 V_{S}^{2}+8 P_{1} R_{2}}
$$

Assigning various values of $S C R$ to (5), the minimum required reactive power is illustrated in Fig. 2(a). As shown, when the grid is strong $(S C R=5,9)$, the minimum reactive power is below zero (inductive reactive power referred to as negative). When the grid is very weak, $S C R=0.9$ for instance, the minimum has to be well above zero. This minimum reactive is not monotonic for a bidirectional power flow.

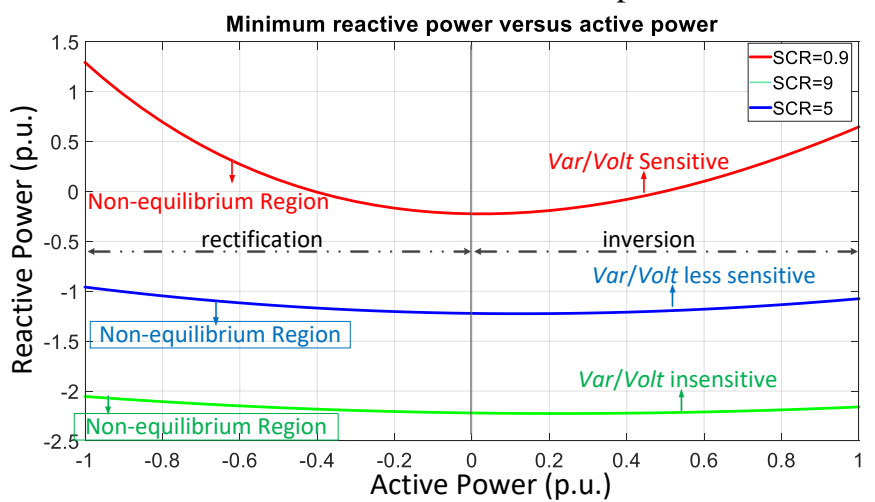

(a) non-equilibrium region with Variable SCR

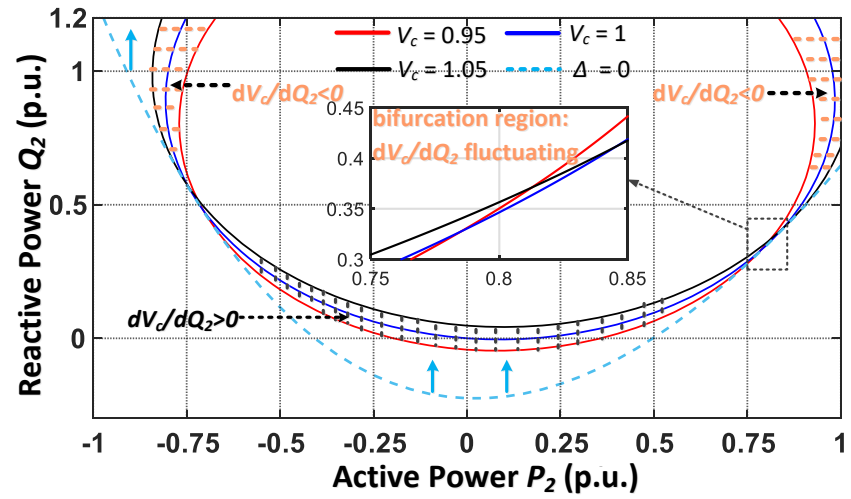

(b) operating region when $\mathrm{SCR}=0.9$

Fig. 2. Equilibrium region in $Q-P$ plane

Keeping irrelevant variable constant in (3), the static sensitivity of voltage in respect to reactive power can be obtained as

$$
\frac{d V_{C}}{d Q_{2}}=\frac{V_{C}^{2} \omega L_{2}-R_{2}^{2} Q_{2}-\omega^{2} L_{2}^{2} Q_{2}}{2 V_{C}^{3}-V_{C}\left(2 Q_{2} R_{2}+V_{S}^{2}\right)-2 V_{C} \omega L_{2} Q_{2}}
$$

, which is a non-linear and non-monotonic function of grid condition and operating power.

By keeping $V_{\mathrm{c}}=0.95,1$ and 1.05 p.u., the $Q-P$ curve of $S C R=0.9$ is illustrated in Fig. 2(b). As shown, to reach the physical limit of active power between the curves of $V_{c}=0.95$ and 1.05 p.u., the equilibrium point has to withstand with both positive voltage sensitivity $\mathrm{d} Q / \mathrm{d} V>0$ (for low power) and negative voltage sensitivity $\mathrm{d} Q / \mathrm{d} V<0$ (for high power).

To prevent voltage collapse, a robust reactive power compensation scheme is essential to ensure the existence of voltage equilibrium and to mitigate the impact of negative voltage sensitivity simultaneously.

\section{Securing an equilibrium point with var/volt regulation}

In this section, the advantage of var/volt droop is mathematically proved in terms of two aspects: 1) ensure a real solution of equilibrium voltage against unknown low grid strength; 2) suppression of voltage variation.

Considering a feedback var/volt droop with a reference voltage $V_{C}^{*}$ as

$$
K=\frac{Q_{2}}{V_{C}^{*}-V_{C}}
$$

and substitute (8) into (3), there is

$V_{C}^{4}+2 \omega L_{2} K V_{C}^{3}-2 K^{2} V_{C}^{*}\left(\omega^{2} L_{2}^{2}+R_{2}^{2}\right) V_{C}$

$+K^{2}\left(\omega^{2} L_{2}^{2}+R_{2}^{2}\right) V_{C}^{* 2}+\left(\omega^{2} L_{2}^{2}+R_{2}^{2}\right) P_{2}^{2}$

$+\left(-2 P_{2} R_{2}-V_{S}^{2}-2 \omega L_{2} K V_{C}^{*}+K^{2} \omega^{2} L_{2}^{2}+K^{2} R_{2}^{2}\right) V_{C}^{2}$

$=0=f\left(V_{C}\right)$

Since $f\left(V_{C}\right)$ is $2^{\text {nd }}$ order differentiable, to secure an equilibrium point within the maximum voltage deviation $\Delta V_{\text {max }}$ from the reference value $V_{C}^{*}$, one sufficient condition to ensure the existence of $V_{C}$ within $\left[V_{C}^{*}-\Delta V_{\text {max }}, V_{C}^{*}+\Delta V_{\text {max }}\right]$ is

and

$$
f\left(V_{C}^{*}-\Delta V_{\max }\right)<0
$$

$$
f\left(V_{C}^{*}+\Delta V_{\max }\right)>0
$$

Considering $f\left(V_{C}\right)$ as a function of $K,(8)$ can be re-arranged as

$$
\begin{aligned}
& l(K)=f\left(V_{C}\right) \approx\left(\frac{1}{S C R}\left(V_{C}^{*}-V_{C}\right) K+V_{C}\right)^{2}-V_{C}^{2}+V_{C}{ }^{4}+\left(-2 P_{2} R_{2}-\right. \\
& \left.V_{S}^{2}\right) V_{C}^{2}+\frac{P_{2}^{2}}{S C R^{2}}
\end{aligned}
$$

and its differential in respect to $K$ can be obtained as

$$
\begin{aligned}
& l^{\prime}(K)=2\left(\frac{1}{S C R}\left(V_{C}^{*}-V_{C}\right) K+V_{C}\right) \frac{1}{S C R}\left(V_{C}^{*}-V_{C}\right) \\
& =\left\{\begin{array}{c}
-\left.2\left(-\frac{\Delta V_{\max }}{S C R} K+V_{C}^{*}-\Delta V_{\max }\right) \frac{\Delta V_{\max }}{S C R}\right|_{V_{C}=V_{C}^{*}-\Delta V_{\max }} \\
\left.2\left(\frac{\Delta V_{\max }}{S C R} K+V_{C}^{*}+\Delta V_{\max }\right) \frac{\Delta V_{\max }}{S C R}\right|_{V_{C}}=V_{C}^{*}+\Delta V_{\max }
\end{array}\right.
\end{aligned}
$$

Combining (12) with the following practical constraints

$K>0,0<\Delta V_{\text {max }} \ll 1, S C R>0,0<V_{C}^{*} \approx 1,-1 \leq P_{2} \leq 1$

when

$$
\frac{V_{C}^{*}}{\Delta V_{\max }}>\frac{K}{S C R}+1
$$

, for any valid value of $\Delta V_{\max }, V_{C}^{*}, S C R, P_{2}$, there is

$$
\left\{\begin{array}{l}
\left.l^{\prime}(K)\right|_{V_{C}=V_{C}^{*}-\Delta V_{\text {max }}}<0 \\
\left.l^{\prime}(K)\right|_{V_{C}=V_{C}^{*}+\Delta V_{\text {max }}}>0
\end{array}\right.
$$

, which implies that within the range of (14)(15), a greater value of $K$ contributes to satisfying (10) and (11), and is therefore more robust to ensure an equilibrium point in the interested range $\left[V_{C}^{*}-\Delta V_{\max }, V_{C}^{*}+\Delta V_{\max }\right]$.

Once an equilibrium voltage exists, var/volt droop can linearize the $Q-V$ process. As is demonstrated by the 
simplified block diagram in Fig. 3, where $H(\mathrm{~s})$ is the plant of $V_{c}(\mathrm{~s}) / q_{2}(\mathrm{~s})$ and the simplified closed-loop transfer function is

$$
V_{c}(s) / V_{c}^{*}=K H(s) /(1+K H(s))
$$

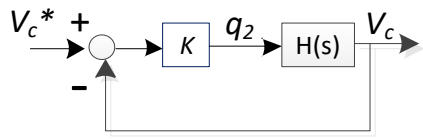

Fig. 3 Simplified Block Diagram of Voltage Control

From (17) and Fig. 3, when $|K H(s)|>>1$, there is $V_{c} / V_{\text {ref }} \approx 1$. This implies that if the droop gain is sufficiently large, it will force the local voltage to settle in close vicinity of the reference value and mitigate the impact of grid strength variations at steady state.

\section{Numerical design for a practical var/volt droop}

As an illustration, the most adverse condition of VSCHVDC integration in GB power network is reported to be an $S C R$ between 1.2 and 6 [2]. Given a declining grid strength in reality, $S C R=0.9$ is considered as an adequate boundary in this paper. Considering an $X / R$ ratio as $\omega L_{2} / R_{2}=10$ and sensibly assuming $V_{C} V_{G} \approx 1$ for simplicity, the required reactive power can be solved with the constraint of (1) and (2) re-organized as (18) and (19)

$$
\begin{gathered}
Q_{2} \leq V_{C} V_{S} \cdot \frac{1}{R_{2}}+p_{2} \cdot \frac{\omega L_{2}}{R_{2}} \\
Q_{2} \geq-V_{C} V_{S} \cdot \frac{1}{R_{2}}+P_{2} \cdot \frac{\omega L_{2}}{R_{2}}
\end{gathered}
$$

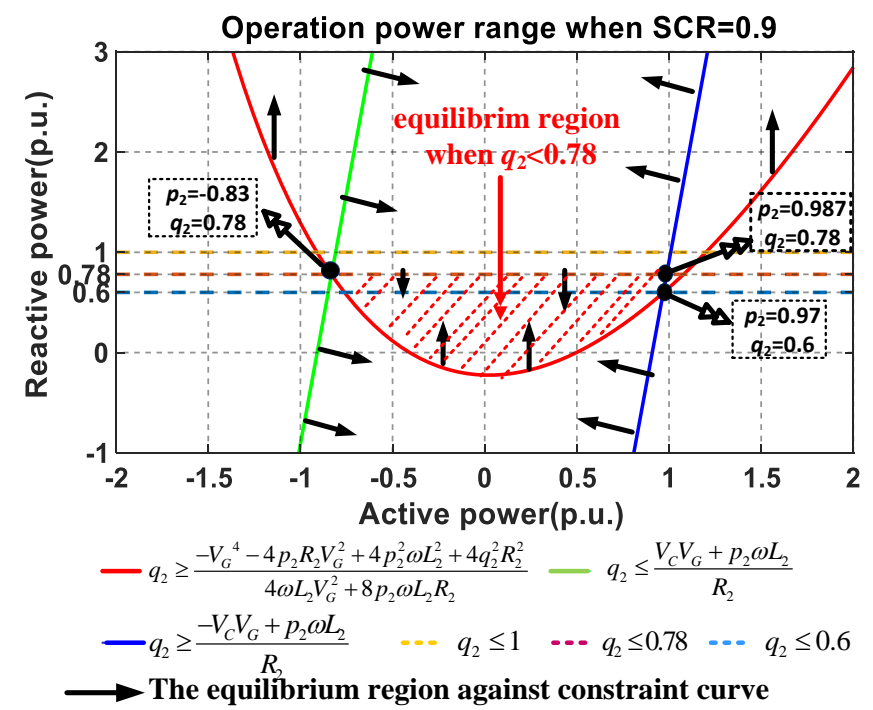

Fig. 4. Static operating region in an extremely weak grid

When the grid is extremely weak, (18)(19) becomes a significant constraint. This is visualized in Fig. 4. It can be seen that to enable an active power of 0.987 p.u., the reactive power has to be above 0.78 p.u.; and the minimum reactive power has to go up to 1 p.u. to enable an active power of 1.01 p.u.. Meanwhile, it could also be found that the rectifying active power (DC to AC) cannot exceed -0.83 p.u. due to the constraint denoted by (18), the green curve. Therefore, for an optimal usage of converter rating, a sensible range of active power is considered between -0.83 p.u. to 0.987 p.u., which corresponds to a maximum reactive power $Q_{2 \max }=0.78$ p.u..
The minimum local voltage to satisfy Inequs. (1)(2)(14) can be obtained as

$$
V_{C} \geq \frac{P_{1}-Q_{2} R_{2} S C R}{S C R \cdot V_{S}}
$$

where (20) is obtained by substituting $\omega L_{2} \approx 1 / S C R$ into (1) considering (14). The largest steady state voltage deviation occurs when the reactive power reaches the highest magnitude. To optimize the converter rating, the maximum voltage deviation $\Delta\left|V_{C}\right|_{\max }$ should correspond to maximum power according to (6). Therefore, the reference voltage can be obtained by combing (8)(20) as

$$
V_{C}^{*} \geq\left(Q_{2 \max }-Q_{C}\right) / K+\frac{P_{1}-Q_{2} R_{2} S C R}{S C R \cdot V_{S}}
$$

In reality, the permitted voltage variation is usually between $5 \%$ to $10 \%$; therefore, a voltage deviation of $\Delta V_{C_{\max }}=3 \%$ is illustrated in this paper. Assigning a sensible size of shunt capacitor as $Q_{\mathrm{c}}=0.1$ p.u., droop gain can be obtained with (8) as $K=(0.78-0.1) / 3 \%=22$ And then, the reference $V_{C}^{*}=$ 1.04 p.u. can be obtained with (21) by assigning the boundary values as $P_{l}=0.987$ p.u., $Q_{2}=0.78$ p.u., $S C R=0.9$ when $V_{\mathrm{s}}=$ 1 p.u..

To sum up Section II, it has been proved that a local var/volt droop of high stiffness is a desirable option to secure an equilibrium voltage against unknown grid strength. However, such design has not taken the impact of EMT process into account, which is inadequate for stabilization.

\section{EMT DYNAMIC ANALYSIS AND THE PROPOSED DAMPING ENHANCEMENT CONTROL}

\section{A. Analytical model in frequency domain and initial settings}

To further find out how the var/volt droop may affect the small-signal damping including electromagnetic dynamics, an analytical model in frequency domain is established. In this model, the electromagnetic transient dynamics of inductive and capacitive elements, PLL, coordinate transformations, current control are considered altogether [20][25].

By aligning the d-axis with the voltage vector of the main grid, the electrical circuit is modeled as (22), and the associate state space is defined in (23) and (24).

$$
\begin{aligned}
x & =\left[i_{c d} i_{c q} V_{c d} V_{c q} i_{2 d} i_{2 q}\right]^{T} u=\left[V_{s d} V_{s q} V_{c o n v d} V_{c o n v q}\right]^{T} \\
A & =\left[\begin{array}{cccccc}
-\frac{R_{1}}{L_{1}} & \omega & -\frac{1}{L_{1}} & 0 & 0 & 0 \\
-\omega & -\frac{R_{1}}{L_{1}} & 0 & -\frac{1}{L_{1}} & 0 & 0 \\
\frac{1}{C} & 0 & 0 & -\omega & -\frac{1}{C} & 0 \\
0 & \frac{1}{C} & \omega & 0 & 0 & -\frac{1}{C} \\
0 & 0 & -\frac{1}{L_{2}} & 0 & -\frac{R_{2}}{L_{2}} & \omega \\
0 & 0 & 0 & \frac{1}{L_{2}} & -\omega & -\frac{R_{2}}{L_{2}}
\end{array}\right] \quad B=\left[\begin{array}{cccc}
0 & 0 & \frac{1}{L_{1}} & 0 \\
0 & 0 & 0 & \frac{1}{L_{1}} \\
0 & 0 & 0 & 0 \\
0 & 0 & 0 & 0 \\
-\frac{1}{L_{2}} & 0 & 0 & 0 \\
0 & -\frac{1}{L_{2}} & 0 & 0
\end{array}\right]
\end{aligned}
$$

By incorporating (22) with the small-signal model of current control, coordinate transformation and PLL, a comprehensive frequency domain model is established as Fig. 5 (a) shows.

In the model shown by Fig. 5 (a), where $K_{p d}$ and $K_{i d}$ refer to the PI regulator gains of the $d$-axis current loop, respectively; $K_{p q}$ and $K_{i q}$ the proportional and integral gains of the q-axis current loop. In the rest of the paper, the gains of PI regulators for $\mathrm{d}$ - and q- current loops are set to make 
bandwidths of both current loops at $50 \mathrm{~Hz}$ (when connecting to an infinite bus) [20]; $K_{p P L L}$ and $K_{i P L L}$ the proportional and integral gains of PLL, which are set to make a natural frequency of $5 \mathrm{~Hz}$ and damping coefficient of 1 when tracking a stiff 3-phase source [20]; $\delta_{0}$ the operating power angle between VSC capacitor and the main grid. $V_{c d}$ and $V_{c q}$ refer to the capacitor voltage components in d-and q-axis; $V_{c o n d}$ and $V_{c o n q}$ are referred to as the converter voltage components in dand q-axis, respectively. $V_{c d 0}$ and $V_{c q 0}$ are the operational points of the capacitor voltage in $\mathrm{d}$ - and q- axis. The input and output signal of the electrical plant is shifted by the power angle $\delta_{0}$, to adapt to the voltage reference frame aligned with the capacitor voltage for VSC control. The delay caused by digital control is modeled as a first order process with a time constant of $\tau$, which is set at $0.002 \mathrm{~s}$ for a switching frequency of $2.5 \mathrm{kHz}$ each cycle and symmetrical pulse width modulation [34][35] for an adverse control delay.

The signal $i_{c d} *$ comes from the output of the power loop. As is shown in Fig. 5(c), the power loop is a feed-forward process with the assistance of an integral control. $V_{\mathrm{cn}}$ is the nominal voltage. For simplicity, the integral gain is assumed sufficiently small that its dynamics is negligible.

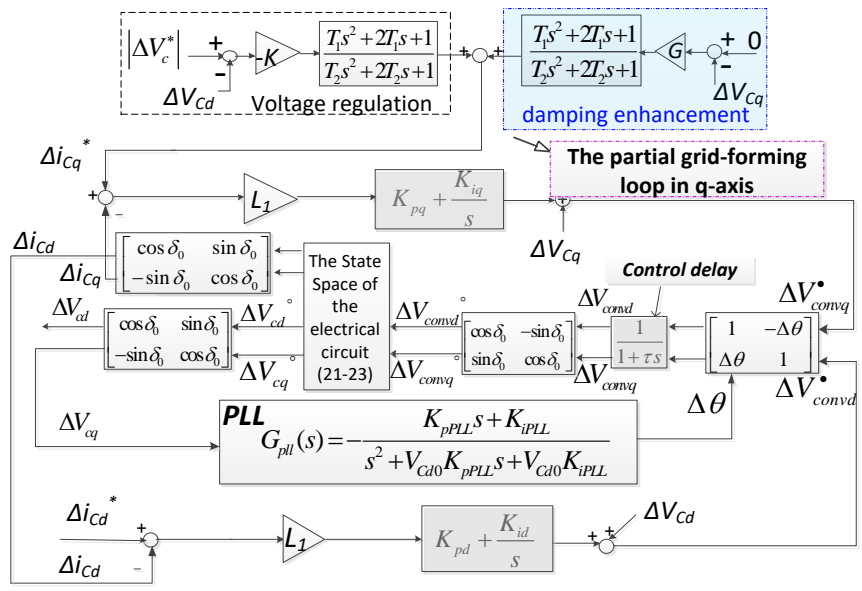

(a) Analytical model of VSC in frequency domain

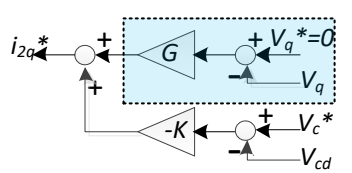

(b) Uncompensated partial grid-forming Fig. 5. Analytical model of the VSC

\section{B. The dynamic impact a standard var/volt droop}

From this section on, all initial parametric settings are by default as what is suggested in Section II-D and III-A unless otherwise stated. The operational point of full power inversion corresponding to (22) is calculated as

$x_{0}=[0.7584 ; 0.8724 ; 0.1428 ; 1.016 ; 0.86 ; 0.8866]^{T}$

$u_{0}=[1 ; 0 ; 0.09 ; 1.1636]^{T}$

With "the voltage regulation" and the "partial grid-forming loop" replaced by a standard var/volt droop according to (7) and Fig. 3 in the model of Fig. 5(a), root locus analysis is carried out against an increased gain value of $K$, as Fig. 6 shows. As illustrated, when $S C R=9$, the increased value of $K$ from 0 to 9.5 can initially improve system damping by pushing the main pole towards the left side; this damping improvement saturates when $K$ is around 4.5, and then increasing $K$ starts to degrade damping thereafter. When the grid becomes weaker as $S C R=3$, damping improvement saturates earlier around $K=2.5$.
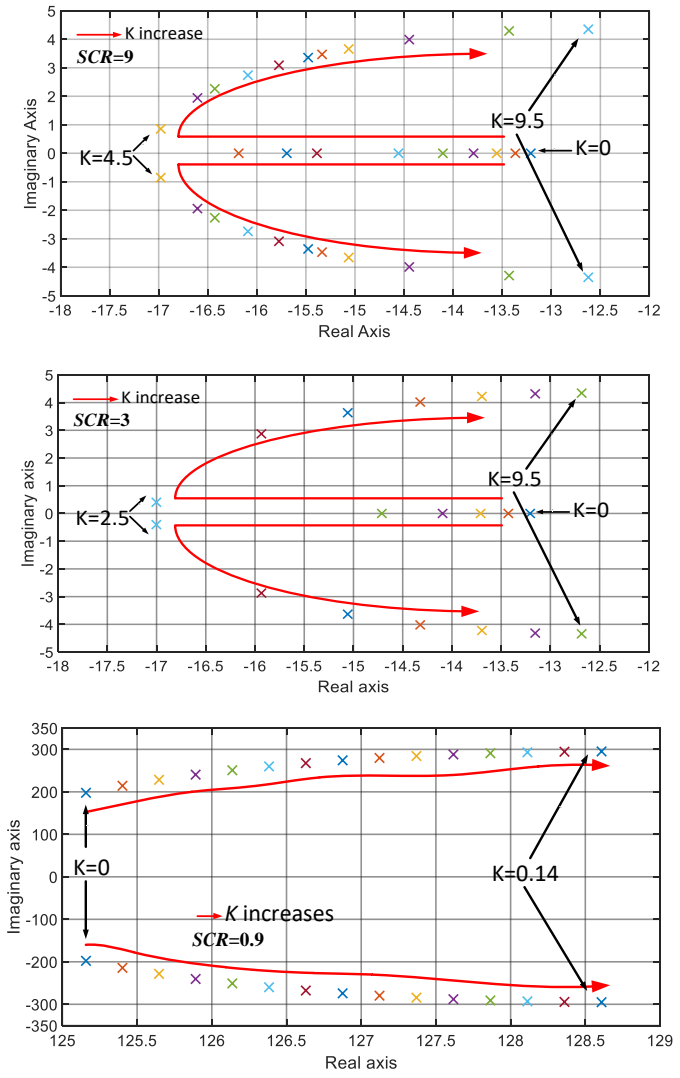

Fig. 6. Root locus against the gain of volt/var droop with variable SCR

To enable larger values of droop, lead-lag compensators are commonly used to fix the gain margin at low frequencies [32]. This approach is based on a presumption that there is a positive gain margin when the gain is sufficiently small. Such presumption is valid for the cases as $S C R=3,9$ in Fig. 6 . However, when the grid becomes extremely weak, as the case of $S C R=0.9$ in Fig. 6, there is no positive margin from $K=0$; therefore, neither gain tuning nor any lead-lag compensator alone can stabilize the system in this case. From physical point of view, since the operating point is within the region of $\mathrm{d} Q / \mathrm{d} V<0$ shown in Figure 2(b), a positive feedback is introduced by the var/volt droop of (7) at $0 \mathrm{~Hz}$ in d-q frame, which cannot be compensated.

Therefore, to stabilize the system, the control structure has to be modified. Since the analysis in this section keeps PLL setting identical to strong grids, this instability mechanism is independent from PLL.

\section{Damping enhancement and its small-signal analysis}

To mitigate the impact of the positive feedback introduced by reactive compensation, a partial grid-forming feedback control is proposed, which is shown in Fig. 5(b). This design is based on 3 considerations: 
1) Considering a reactive power perturbation $\Delta q_{p}$ injected to the local bus, it will lead to q-axis current perturbation $\Delta i_{p}=-\Delta q_{p} / V_{c 0}$. According to the electromagnetic dynamics of (22)-(24), there is

$$
\begin{aligned}
C d \Delta V_{C q} / d t=\Delta i_{p} & =-\Delta q_{p} / V_{c 0} \\
\frac{d \Delta i_{2 q}}{d t} & \approx \frac{\Delta V_{C q}}{L_{2}}
\end{aligned}
$$

Substitute (26) into (25) yields

$$
\frac{d \Delta i_{2 q}}{d t} \approx \frac{-1}{L_{2} C V_{C 0}} \int \Delta q_{p} d t
$$

, which implies that a positive reactive power perturbation tends to decrease q-axis current on the grid side. When the operating power is sufficiently high to enter the region of $\mathrm{d} Q / \mathrm{d} V<0$ (for both inversion and rectification), the var/volt droop will initiate the fore cited positive feedback, which is demonstrated in Fig. 7. However, according to (25) and shown in Fig. 7, this process has to gone through an EMT process (charge the local capacitance $C$ ) to close the loop.

With an additional partial grid-forming loop in Fig. 7, this capacitive transient in q-axis is compensated with a negative feedback control over $\Delta V_{C q}$. Thus, one chain of the positive feedback loop is broken.

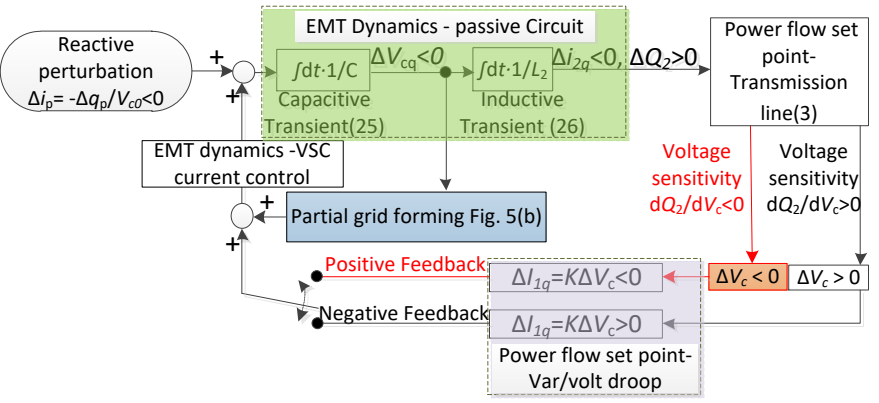

Fig. 7. Simplified principle of instability and electromagnetic stabilization

2) Due to the presence of PLL, the steady state value of $V_{c q}$ converges at 0 . By setting the reference value of $V_{c q}$ at 0 , the steady state output of the regulator will also settle at zero. Thus, the operating states will not be shifted by this auxiliary control, including voltages, powers and currents. Physically, it means that this added loop will not consume any current at steady state.

3) From the view point of classical control theory, an added negative feedback can improve system damping by shifting the distribution of poles [30].

By replacing "voltage regulation" and "partial grid-forming loop" in Fig. 5(a) with the controls in Figs. 5(b), a root locus is obtained with an adverse condition of $S C R=0.9$ and $K$ up to 25, as Fig. 8 shows.

As is indicated by the red arrow in Fig. 8, increasing the value of $K$ to 25 can adversely bring the real component of the main pole as far as 1600 ; whereas by introducing the partial grid-forming loop, the main pole can be pushed back towards the left plane when gain of the partial grid-forming loop $G$ increases, indicated by the blue pointer. However, this improvement is saturated when the real component is approximately 100 in the right plane. This means that an uncompensated q-axis partial grid-forming loop shown in Fig. 5 (b) is inadequate for stabilization.

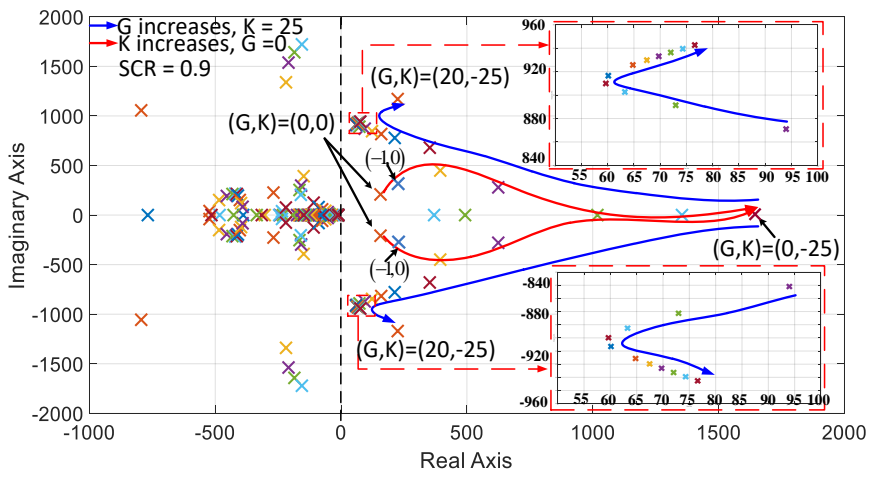

Fig. 8. Root locus for standard var/volt droop and simple virtual conductance

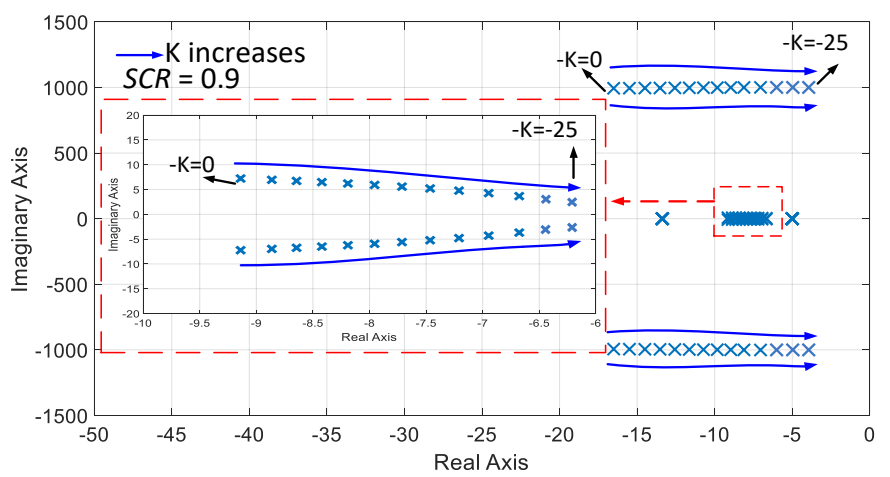

Fig. 9. Root locus with the proposed outer loop control

To further improve small-signal damping, a $2^{\text {nd }}$ order leadlag controller $\left(\frac{T_{1} s+1}{T_{2} s+1}\right)^{2}$ is proposed for the input of q-axis current as shown in Fig. 5 (a). By setting $G=16$, a pre-fixed constant as $T_{2}=0.2 \mathrm{~s}$ and $T_{1}=0.04 \mathrm{~s}$, root locus against the var/volt gain is again depicted in Fig. 9, with identical operational points used in Fig. 8.

As indicated by the blue arrow in Fig. 9, "the proposed damping outer loops" changes the distribution of the main poles from Fig. 8. Although the increased $K$ value is still pushing the main poles towards the right plane, all the poles are distributed within the left plane while the range of $K$ is unchanged. This indicates that the proposed outer loop control approach can effectively accommodate the conflict between var/volt droop and small-signal stability in this case.

Given the volume of control parameters, i.e. gains of PI control, PLL, $2^{\text {nd }}$ order regulator, etc., it is impractical to tune all of them analytically. Instead, this paper recommends fixed heuristic settings in p.u. and specifies the applicable conditions. Given a sensible range of grid strength, the prefixed parameters, along with the proposed control, have demonstrated stability in frequency domain, which indicates an expected robustness in time domain.

\section{Time domain case studies}

To verify the robustness of the proposed outer loop control against variable grid conditions, a time domain case study is carried out based on the instantaneous average converter model so electromagnetic dynamics are reflected.

To test the robustness of the control against full range of active power, a power ramp test of 0.25 p.u./sec for full delivery range is carried out in Fig. 10(a), the test starts with 
the situation when the VSC is connecting to a strong grid of $S C R=9$. And then, a ramp order for $i_{\mathrm{d}}$ is given at a rate of 0.25 p.u./s till 1 p.u.. After the ramp has reached 1 p.u., the ramp heads down towards -0.83 p.u. with a ramp of -0.25 p.u./sec. After staying at 0.83 p.u. for a few seconds, the ramp heads back to 0 p.u.. Throughout this test cycle, the control setting is unchanged and maximum reactive current demand is no more than 0.16 p.u.. Due to the use of a strong Var/Volt droop, the voltage is almost at the same level as the grid side. This shows that the settings designed for an extremely weak grid is compatible with a strong grid.

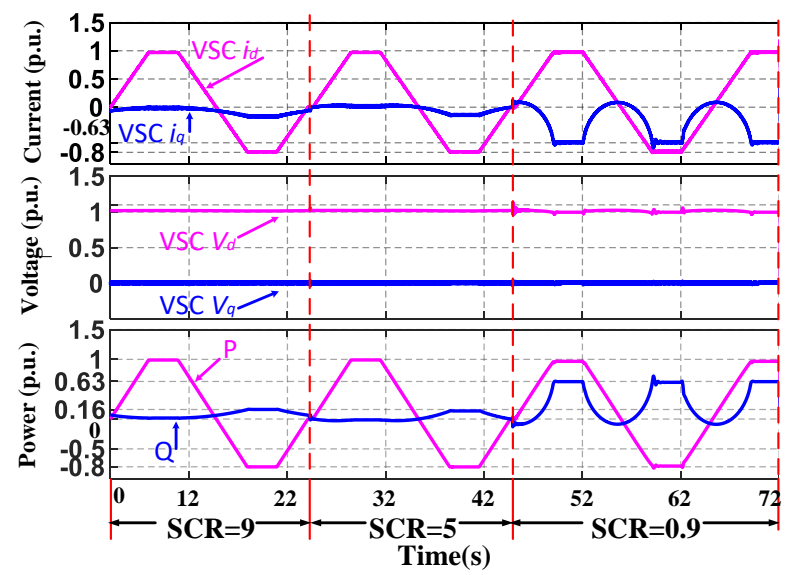

(a) power ramp test with less-intrusive stabilization

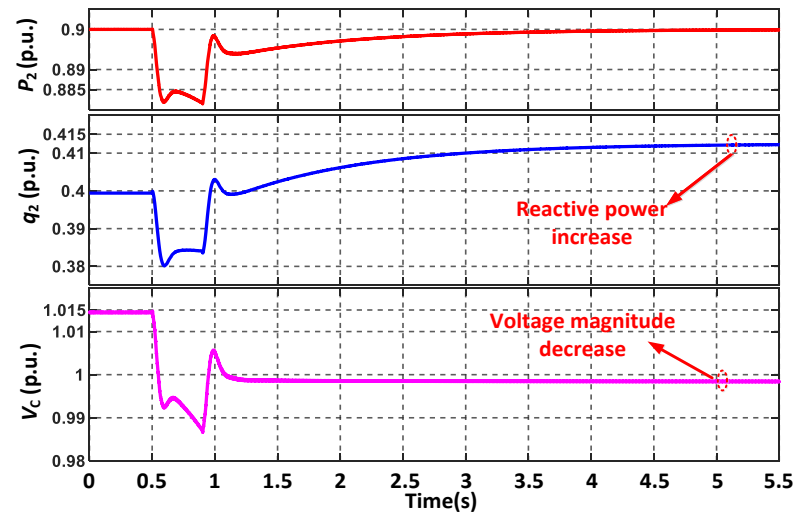

(b) reactive power change in a region of $\mathrm{d} V / \mathrm{d} Q<0(S C R=0.9)$

Fig. 10. EMT Power ramp test with less-intrusive stabilization

To test the robustness against SCR variation, at Time $=24 \mathrm{~s}$ in Fig. 10(a), an SCR change is emulated to switch SCR to 5. Then, the ramp test cycle repeats. It can be seen that the responses of voltage and reactive current are hardly changed, which demonstrate rather consistent performance in strong grid.

At time $=45 \mathrm{~s}$ in Fig. 10(a), another $S C R$ change is made to bring $S C R$ to 0.9 . When the ramp limit of 1 p.u. and -0.83 p.u., is reached, the reactive power autonomously reached approximately 0.63 p.u., which corresponds well to Fig. 4, given a local capacitor of 0.1 p.u.. The voltage is dropped by approximately 0.03 p.u. at steady state. This is a result from the strong var/volt droop and corresponds to the design with (8). It also worth mentioning that when Time $=48 \mathrm{~s} \sim 53 \mathrm{~s}$ and Time $=48 \mathrm{~s} \sim 53 \mathrm{~s}$, the operating power is above 0.8 p.u. when $V_{\mathrm{c}}>1.0$ and $S C R=0.9$, which is in the region of $\mathrm{d} V_{\mathrm{c}} / \mathrm{d} Q_{2}<0$.

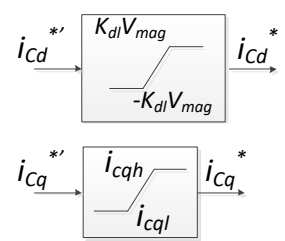

(a) Current saturations Fig. 11. Dynamic current saturation

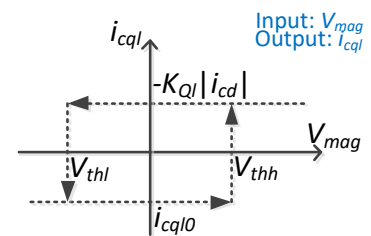

(b) hysteresis for q-axis current lower limit
Throughout the ramp test in Fig. 10(a), $K$ is fixed at 22 and the rest of parameters are identical to the ones used in Fig. 9. This time domain simulation result corresponds to the analysis of frequency domain against SCR variations in Section III-C.

To further verify the control in the region of $\mathrm{d} Q / \mathrm{d} V<0$, a reactive change is tested in Fig. 10(b), in which the active power starts at 0.9 p.u. when $S C R=0.9$. At time $=0.5 \mathrm{~s}$ in Fig. 10(b), a reactive power disturbance is added to the VSC order which eventually leads to an increase of reactive power from 0.4 to 0.412 p.u.. Due to a power loop, the active power recovers 0.9 p.u. after the transient, but the voltage $V_{\mathrm{c}}$ drops from 1.015 p.u. to 0.998 p.u., which implies that an increase of reactive power to the grid is decreasing local voltage so the system is operating in an $\mathrm{d} Q / \mathrm{d} V<0$ region. This well corresponds to the situation estimated in Fig. 2(b) and shows that with the proposed electromagnetic damping scheme, voltage collapse is avoided successfully.

To test the impact of the proposed control to transient response, a fault-ride-through test is carried out. A dynamic current saturation strategy is employed to facilitate the process. As is shown by Fig. 11 (a), during significant voltage transient, the d-axis current order $i_{c d} *$ is capped in proportion with $K_{d l} V_{\text {mag }}$, where $V_{\text {mag }}$ is the magnitude of the capacitor voltage in per unit and $K_{d l}$ is a positive constant. As is show by Fig. 11(b), a hysteresis is used to determine the lower limit of qaxis current, $i_{c q l}$. The value of $i_{c q l}$ is dynamically set at $-K_{q l}\left|i_{C d}\right|$ to avoid excessive reactive current at steady state in normal state; whereas, when the voltage dropped below a threshold $V_{t h l}$, a fixed saturation point, $i_{c q 0}$, is set to limit the current magnitude.

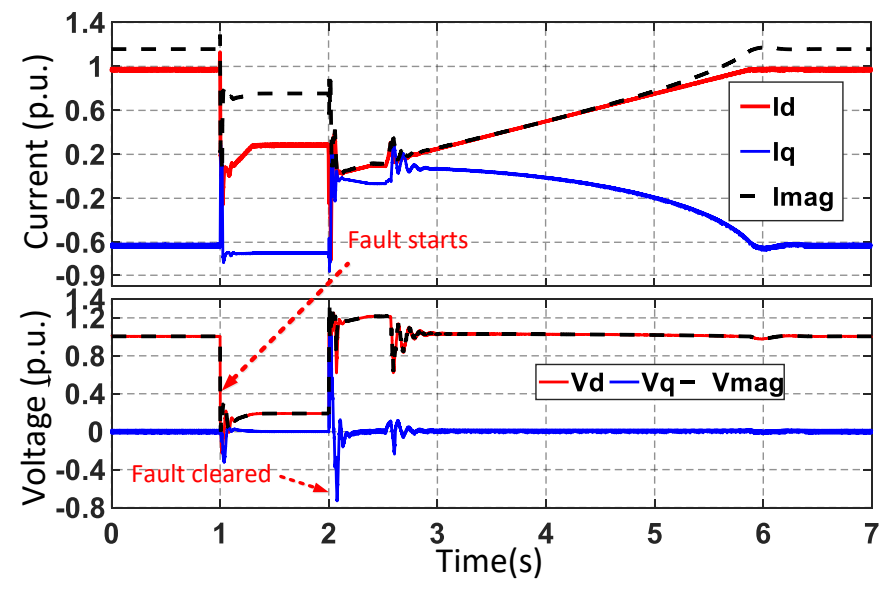

(a) Extremely weak grid $(\mathrm{SCR}=0.9)$ with stabilizer 


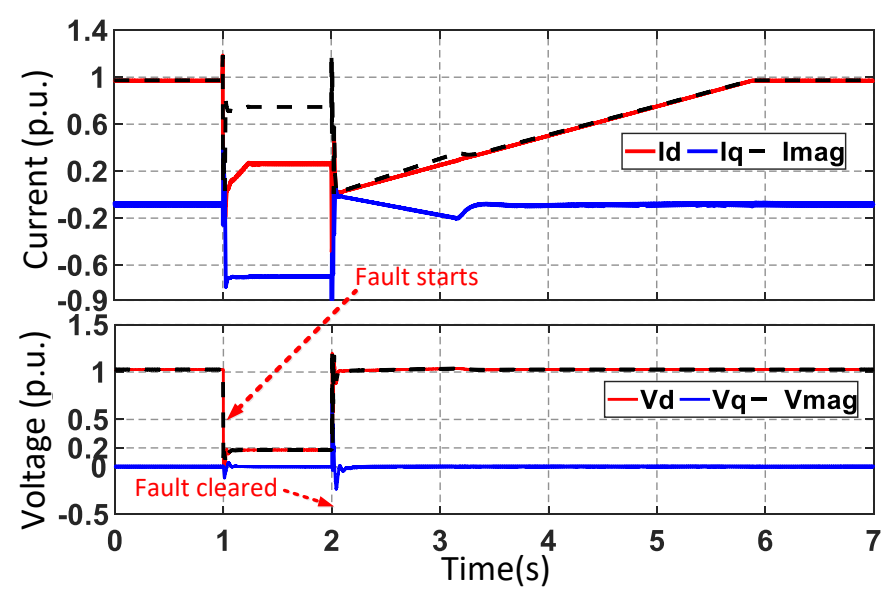

(b) Strong grid ( $\mathrm{SCR}=9)$ with stabilizer

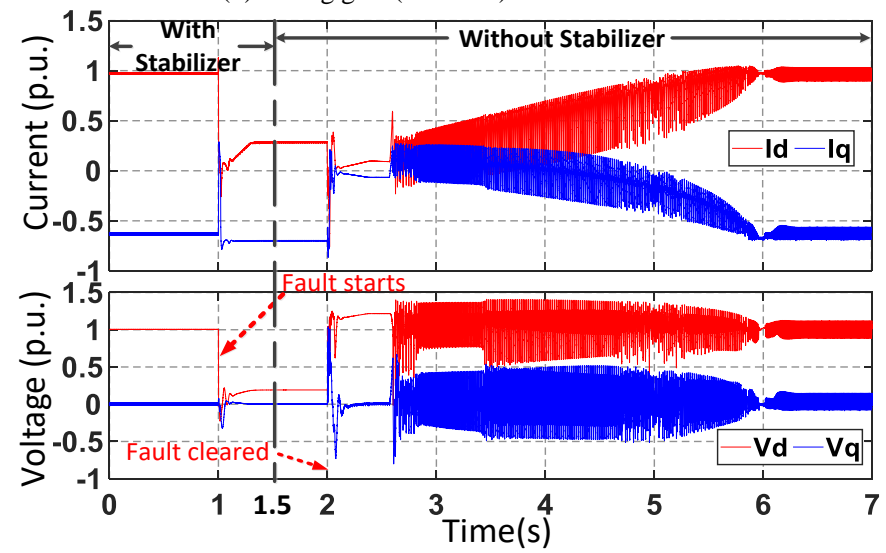

(c) Extremely weak grid ( $\mathrm{SCR}=0.9)$ with stabilizer disabled during the fault Fig. 12. Fault-ride-through test with variable grid strength

To illustrate the compatibility of an adverse FRT, specific settings are made as $K_{d l}=1, i_{c q h}=1$ p.u., and $K_{Q l}=0.7$ and the fault-ride-through test is illustrated when $S C R=0.9$ in Fig. 12(a). As shown, the active power starts at 1 p.u. since Time $=$ $0 \mathrm{~s}$; a 3-phase fault happens at Time $=1 \mathrm{~s}$. The fault brings the voltage magnitude to approximately 0.25 p.u.. Due to the dynamic saturation scheme and the presence of inner current loops, d-axis current is regulated at 0.25 p.u. During the fault, the $\mathrm{q}$-axis current is regulated at the pre-defined saturation point -0.7 p.u.. Another fault-ride-through test is demonstrated when $S C R=9$ in Fig. 12(b). As seen, the performance is largely similar to $S C R=0.9$. The main difference introduced by weak grid is more transient oscillations at the fault and clearance. This is expected, as the damping in a weaker grid is degraded while the control settings are unchanged. However, the transient magnitudes of both voltage and current are still within a range of 1.4 p.u. and 0.9 p.u., respectively, which is acceptable.

A further comparison FRT test is provided in Fig. 12(c), where all the condition are identical to the case of SCR $=0.9$ in Fig. 11(a) except for the stabilizer disabled from Time $=1.5$ s. As seem, at the settled point during the fault, the stability is not affected as the VSC is de-loaded; however, when the fault is cleared and the VSC starts to recover the active power, the system starts to oscillate at Time $=2.6 \mathrm{~s}$. This is due to a degraded damping with greater power output [26] and the presence of strong var/volt droop adds up to this negative damping, which leads to oscillation when the VSC loading is below 0.2 p.u..

As the faulty types, FRT strategies and grid codes may vary, the actual FRT performance varies in real world practices. The scope of this paper cannot exhaust all the cases but only illustrates the compatibility with an adverse case. Nonetheless, the preservation of current loops should enable compatibility with other FRT strategies.

\section{Stabilizer as A NON-INTRUSIVE SOLUTION}

In this section, the grid side solution to improve damping is derived. To implement, the proposed damping enhancement control can be carried out by an external stabilizer out with the main VSC.

Since the damping enhancement scheme proposed in Fig. 5(a) completely keeps the inner loops intact and consumes zero current at steady state, the damping can be provided by a free-standing VSC, namely the "zero-current" stabilizer to the AC grid connected.

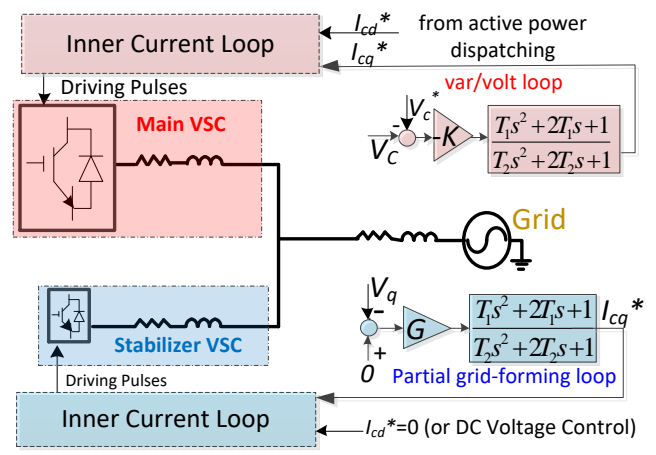

(a) Damping by "zero-current" stabilizer

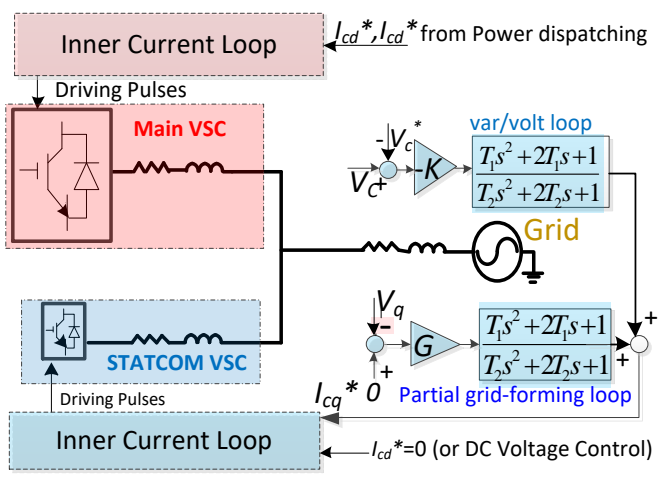

(b) Damping by STATCOM

Fig. 13. Schematics of non-intrusive stabilization

By putting away the delivery of apparent power, the scheme of "zero-current" stabilizer can be derived from Fig. 5(a) as Fig. 13(a) shows. A ramp test is carried out to test in Fig. 14 with the control parameters used in Section III-D. As shown, when d-axis current $i_{\mathrm{d}}$ of VSC ramps up from $\mathrm{t}=0 \mathrm{~s}$ at a rate of 0.25 p.u./s, the reactive current of the main VSC drops to around -0.67 p.u., which again correspond to the analysis in Section II-A. A moderate voltage overshoot of 1.25 p.u. occurs when the ramp stops at Time $=4 \mathrm{~s}$. At the meantime, the stabilizer is consuming zero-current at steady state as expected. After Time $=4 \mathrm{~s}$, a stabilizer transient current of 
0.022 p.u. (peak value) occurs by the stoppage of the power ramp. Such transient is caused by the rate of change of the current ramp. During Time $=6 \sim 9 \mathrm{~s}$ in Fig. 14, the stabilizer is disabled and oscillation immediately occurs. The oscillations disappears immediately after the stabilizer is reenabled at Time $=9 \mathrm{~s}$, which verifies the effectiveness of the external stabilizer.

Practically, the declination of DC voltage caused by semiconductor power losses can be recovered by a DC voltage loop and/or a storage so as to maintain an essential level for modulation [31].

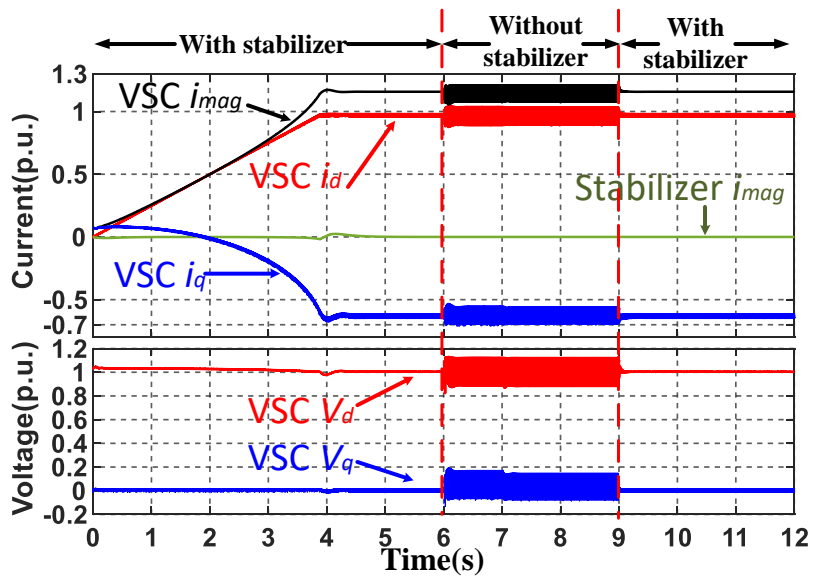

Fig. 14. EMT Ramp test with "zero-current" stabilizer scheme

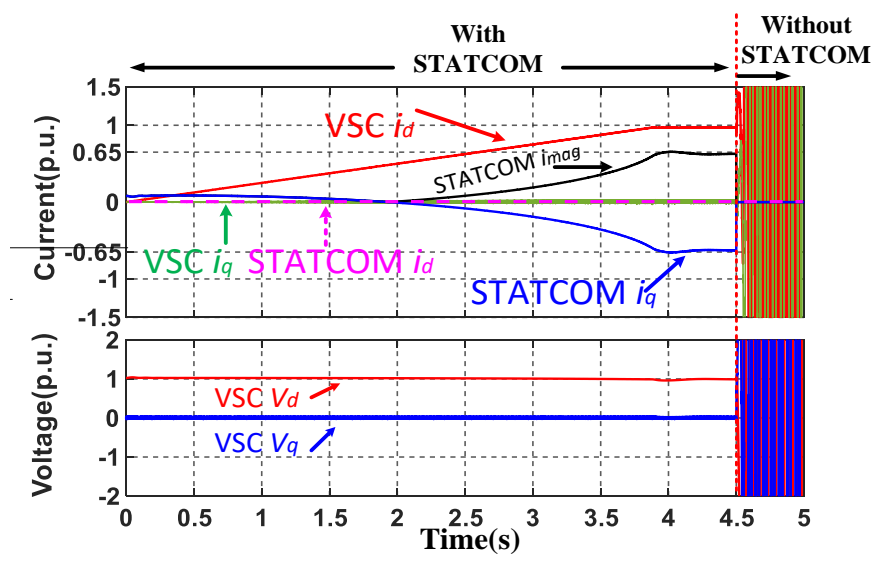

Fig. 15. EMT Ramp test with STATCOM scheme

As an alternative scheme, the damping can be carried out along with var/volt droop externally, which is shown by the "main VSC+STATCOM" in Fig. 13(b). A similar ramp test as Fig. 15 is carried out with such scheme. As shown, the voltage and active power performance is almost identical as the previous "zero-current" scheme in Fig. 14(a); meanwhile, the provision of reactive current is shifted to the STATCOM. Consequently, the current magnitude of STATCOM has come to approximately 0.7 p.u.. When the STATCOM is disconnected in Fig. 15, the system starts to oscillate, which is more violently than Fig. 14. This is because the oscillations are triggered by the non-existence of equilibrium point and this oscillation cannot be mitigated by damping.

Discussion: For "all-in-one" scheme, grid conditions have to be fully predictable at the design stage to optimize the power capacity. For the STATCOM scheme, it is more suitable to "patch" a commissioned VSC with a declining fault level, but considerable reactive power capacity is expected. For the stabilizer scheme, it offers physically plug-and-play solution with zero steady state current.

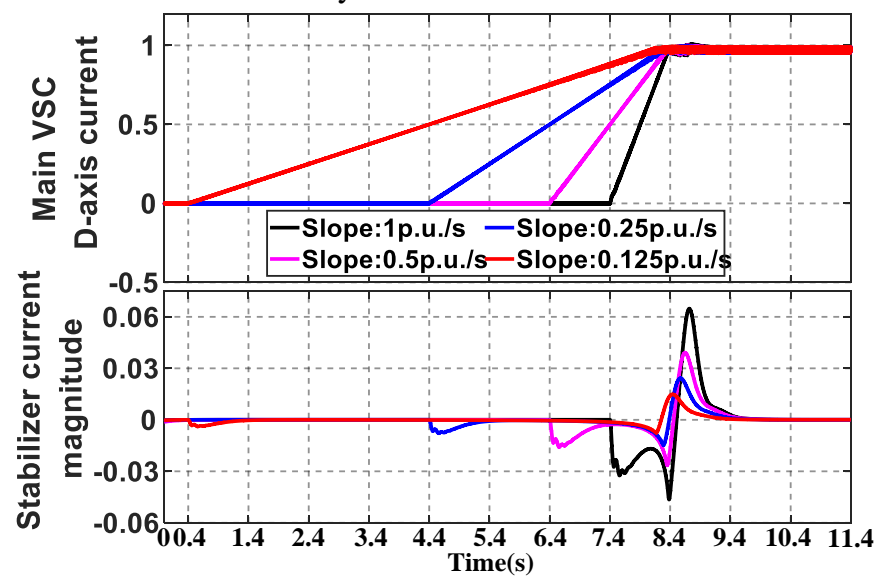

Fig. 16. The comparison of stabilizer transient current

Although the stabilizer is designed to consume zero current at steady state, it does respond to an electro-magnetic transient, i.e. the change of injecting current. To illustrate, a comparison analysis is carried out with various power ramps (of the main VSC), shown by Fig. 16. It can be seen that when a ramp is applied to the main VSC, the peak current of the stabilizer occurs at the stoppage of the ramp. When the ramp is large, at 1 p.u./second for instance, the peak current of the stabilizer can be up to $6.5 \%$ p.u. at Time $=8.7 \mathrm{~s}$. When the ramp is slower, such transient current drops as well. The lowest peak can be down to $1.5 \%$ p.u. for a ramp of 0.125 p.u./s. This reveals that the size of the stabilizer depends on the intended rate of change of active current/power. By reducing the allowed ramp rate of active power, the size of stabilizer can be limited to a low level.

\section{CONCLUSION}

As is summarized in Fig. 17, given a conventional vector control in weak grids, the instability is originated with two causes: 1) non-existence of equilibrium point, 2) negative damping. While a strong var/volt droop is beneficial to secure an equilibrium point with unknown grid strength, it amplifies the negative electromagnetic damping introduced by negative voltage sensitivity $\mathrm{d} Q / \mathrm{d} V<0$. This instability mechanism is independent from tuning of PLL or current loops.

As an auxiliary control, the proposed partial grid-forming loop in q-axis can mitigate the conflict between strong var/volt droop and electromagnetic damping. With a pre-fixed parametric setting (var/volt droop, current regulators, PLL, lead-lag regulator), this scheme can exhaust the physical limit of power delivery in very strong grids as well as extremely weak grids $(S C R=0.9, X / R=10)$. With appropriate control over electromagnetics, the proposed control can cover the operating region of $\mathrm{d} Q / \mathrm{d} V<0$ and support FRT when the grid strength is unknown.

The proposed control also offers an equally effective solution for utilities and/or VSC owners. With such non- 
intrusive solution, there is no need to physically access those commissioned VSCs. Implemented by an external converter, namely a dedicated stabilizer, storage, STATCOM or any VSC, the proposed control can provide electromagnetic damping service to another VSC nearby with no impact on its set points of power flow. The size of the stabilizer is generally proportional to the rate of change of active power and therefore can be limited by capping the rate accordingly.

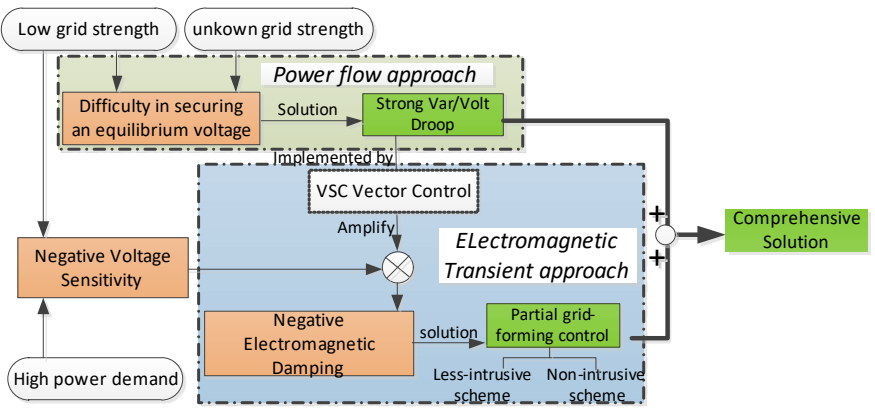

Fig. 17. Instability mechanism and comprehensive solution

\section{REFERENCES}

[1] National Grid ESO, "System Operability Framework Impact of Declining Short Circuit Levels", Dec 2018.

Access: https://www.nationalgrideso.com/document/135561/download

[2] Cameron McHardy, "CMS HVDC System", presented at CaithnessMoray Knowledge Sharing Event, The National HVDC Center, Scottish and Southern Electricity Networks, Glasgow, UK $26^{\text {th }}$ Jun 2019

[3] Q.-C. Zhong and G. Weiss "Synchronverters: Inverters that mimic synchronous generators" IEEE Trans. Ind. Electron. Vol. 58 no. 4 pp. 1259-1267 Apr. 2011.

[4] L. Zhang, L. Harnefors, and H. P. Nee, "Power-Synchronization Control of Grid-Connected Voltage-Source Converters," IEEE Trans. Power Syst., vol. 25, pp. 809-820, 2010.

[5] H. Wu and X. Wang, "Design-Oriented Transient Stability Analysis of Grid-Connected Converters With Power Synchronization Control," in IEEE Trans. Ind. Electron., vol. 66, no. 8, pp. 6473-6482, Aug. 2019.

[6] J. Svensson, "Synchronisation methods for grid-connected voltage source converters," IEE Proceedings - Generation, Transmission and Distribution, vol. 148, no. 3, pp. 229-235, May 2001

[7] Se-Kyo Chung, "A phase tracking system for three phase utility interface inverters," IEEE Trans. Pow. Electron., vol. 15, no. 3, pp. 431-438, May 2000.

[8] L. Liu, H. Li, Y. Xue and W. Liu, "Reactive Power Compensation and Optimization Strategy for Grid-Interactive Cascaded Photovoltaic Systems," IEEE Trans. Pow. Electron., vol. 30, no. 1, pp. 188-202, Jan. 2015.

[9] K. Shi, W. Song, P. Xu, R. Liu, Z. Fang and Y. Ji, "Low-Voltage RideThrough Control Strategy for a Virtual Synchronous Generator Based on Smooth Switching," IEEE Access, vol. 6, pp. 2703-2711, 2018.

[10] L. Zhang, L. Harnefors and H. Nee, "Modeling and Control of VSCHVDC Links Connected to Island Systems," IEEE Trans. Power Syst., vol. 26, no. 2, pp. 783-793, May 2011.

[11] J. Roldán-Pérez, E. J. Bueno, R. Peña-Alzola and A. Rodríguez-Cabero, "All-Pass-Filter-Based Active Damping for VSCs With LCL Filters Connected to Weak Grids," IEEE Trans. Power Electron., vol. 33, no. 11, pp. 9890-9901, Nov. 2018.

[12] X. Wang, J. Yao, J. Pei, P. Sun, H. Zhang and R. Liu, "Analysis and Damping Control of Small-Signal Oscillations for VSC Connected to Weak AC Grid During LVRT," IEEE Trans. On Energy Conversion, vol. 34, no. 3, pp. 1667-1676, Sept. 2019.

[13] X. Zhou et al., "Robust Grid-Current-Feedback Resonance Suppression Method for LCL-Type Grid-Connected Inverter Connected to Weak Grid," IEEE J. Emerg. Sel. Topics Power Electron., vol. 6, no. 4, pp. 2126-2137, Dec. 2018.
[14] H. Liu, L. Li, Y. Liu, D. Xu and Q. Gao, "Passivity Based Damping Design for Grid-Connected Converter With Improved Stability," IEEE Access, vol. 7, pp. 185168-185178, 2019.

[15] A. Wu, Z. Yuan, H. Rao, B. Zhou and H. Li, "Analysis of power transmission limit for the VSC-HVDC feeding weak grid," Journal of Engineering, vol. 2019, no. 16, pp. 2916-2920, 32019.

[16] J. Z. Zhou, A. M. Gole "Rationalisation and validation of de power transfer limits for voltage sourced converter based high voltage DC transmission", IET Gener. Transm. Distrib., 2016, Vol. 10, Iss. 6, pp. $1327-1335$

[17] M. Berg, A. Aapro, R. Luhtala and T. Messo, "Small-Signal Analysis of Photovoltaic Inverter With Impedance-Compensated Phase-Locked Loop in Weak Grid," IEEE Trans. Energy Conv., vol. 35, no. 1, pp. 347-355, March 2020.

[18] Y. Li, L. Fan and Z. Miao, "Wind in Weak Grids: Low-Frequency Oscillations, Subsynchronous Oscillations, and Torsional Interactions," IEEE Trans. On Power Syst., vol. 35, no. 1, pp. 109-118, Jan. 2020.

[19] L. Huang et al., "Grid-Synchronization Stability Analysis and Loop Shaping for PLL-Based Power Converters With Different Reactive Power Control," IEEE Trans. Smart Grid, vol. 11, no. 1, pp. 501-516, Jan. 2020

[20] K. Givaki, D. Chen and L. Xu, "Current Error Based Compensations for VSC Current Control in Weak Grids for Wind Farm Applications," IEEE Trans. Sustainable Energy, vol. 10, no. 1, pp. 26-35, Jan. 2019.

[21] D. Yang, X. Wang, F. Liu, K. Xin, Y. Liu and F. Blaabjerg, "Adaptive Reactive Power Control of PV Power Plants for Improved Power Transfer Capability Under Ultra-Weak Grid Conditions," IEEE Trans. Smart Grid, vol. 10, no. 2, pp. 1269-1279, March 2019.

[22] H. Sun et al., "Review of Challenges and Research Opportunities for Voltage Control in Smart Grids," IEEE Trans. Power Syst., vol. 34, no. 4, pp. 2790-2801, July 2019.

[23] J. Liu et al., "Impact of Power Grid Strength and PLL Parameters on Stability of Grid-Connected DFIG Wind Farm," IEEE Trans. Sustainable Energy, vol. 11, no. 1, pp. 545-557, Jan. 2020.

[24] G. Wu et al., "Analysis and design of vector control for VSC-HVDC connected to weak grids," CSEE Journal of Power and Energy Systems, vol. 3, no. 2, pp. 115-124, June 2017.

[25] A. Egea-Alvarez, S. Fekriasl, F. Hassan and O. Gomis-Bellmunt, "Advanced Vector Control for Voltage Source Converters Connected to Weak Grids," IEEE Trans. Power Syst., vol. 30, no. 6, pp. 3072-3081, Nov. 2015

[26] Y. Li, L. Fan and Z. Miao, "Stability Control for Wind in Weak Grids," IEEE Trans. Sustainable Energy, vol. 10, no. 4, pp. 2094-2103, Oct. 2019.

[27] G. Li, Y. Chen, A. Luo and H. Wang, "An Enhancing Grid Stiffness Control Strategy of STATCOM/BESS for Damping Sub-synchronous Resonance in Wind Farm Connected to Weak Grid," IEEE Trans. Ind. Info., 2020.

[28] L. Huang, H. Xin, Z. Wang, L. Zhang, K. Wu and J. Hu, "Transient Stability Analysis and Control Design of Droop-Controlled Voltage Source Converters Considering Current Limitation," IEEE Trans. Smart Grid, vol. 10, no. 1, pp. 578-591, Jan. 2019.

[29] J. Rocabert, A. Luna, F. Blaabjerg and P. Rodríguez, "Control of Power Converters in AC Microgrids," IEEE Trans. Power Electron., vol. 27, no. 11, pp. 4734-4749, Nov. 2012.

[30] L. Keviczky, etl., "Negative Feedback", in Control Engineering, Singapore: Springer, 2019, pp. 155-199.

[31] G. Xu, L. Xu, D. J. Morrow and D. Chen, "Coordinated DC Voltage Control of Wind Turbine With Embedded Energy Storage System," IEEE Trans. Energy Conv., vol. 27, no. 4, pp. 1036-1045, Dec. 2012.

[32] P. Kundur, Power System Stability and Control. New York: McGrawHill, p.p.766-770, 1994.

[33] N. R. Merritt, C. Chakraborty and P. Bajpai, "New Voltage Control Strategies for VSC-Based DG Units in an Unbalanced Microgrid," IEEE Trans. Sustainable Energy, vol. 8, no. 3, pp. 1127-1139, July 2017.

[34] Texas Instrument, " TMS320F2833x, TMS320F2823x Digital Signal Controllers (DSCs), "accessed on July 2020. https://www.ti.com/lit/ds/symlink/tms320f28335.pdf?ts=159604780657 4\&ref_url=https\%253A\%252F\%252Fwww.ti.com\%252Fproduct $\% 252$ FTMS320F28335

[35] SEMIKRON datasheet, "SKiiP 3614 GB17E4-6DPVL V2" accessed on July 2020.

https://www.semikron.com/dl/servicesupport/downloads/download/sem ikron-datasheet-skiip-3614-gb17e4-6dpvl-v2-20603301.pdf 
APPENDIX I SYSTEM SPECIFICATIONS

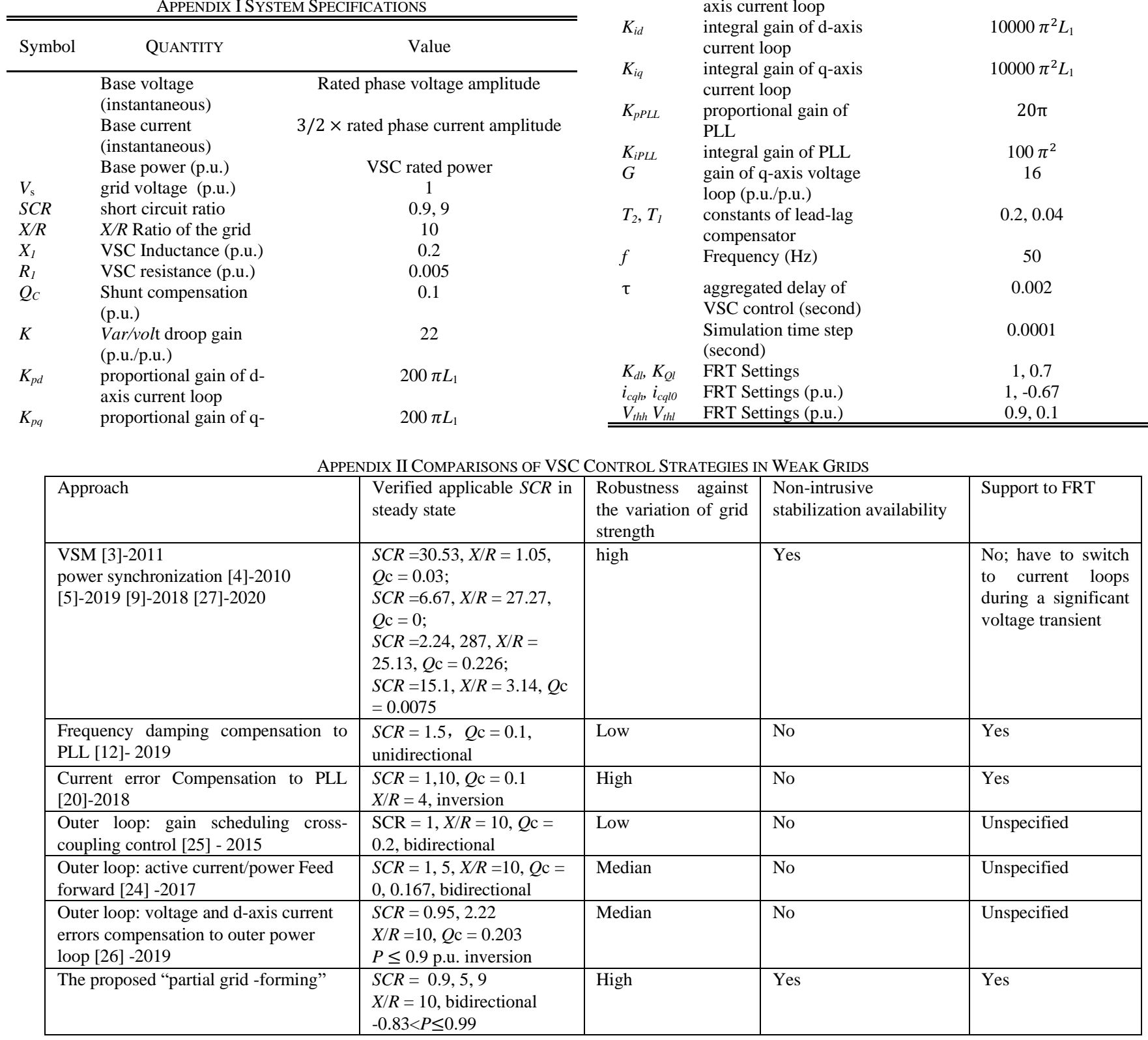

APPENDIX III COMPARISONS OF STABILIZER, STATCOM AND SYNCHRONOUS CONDENSER

\begin{tabular}{|l|l|l|l|}
\hline & Synchronous Condenser & STATCOM & $\begin{array}{l}\text { The proposed non-intrusive } \\
\text { stabilizer }\end{array}$ \\
\hline $\begin{array}{l}\text { Stabilization with } \\
\text { power flow approach }\end{array}$ & Yes & Yes \\
\hline $\begin{array}{l}\text { Stabilization with } \\
\text { electromagnetic transient } \\
\text { approach }\end{array}$ & No & $\begin{array}{l}\text { Originally no, but can be enabled by } \\
\text { embedding the proposed control }\end{array}$ & Yes \\
\hline $\begin{array}{l}\text { Robustness against polarity } \\
\text { change of voltage sensitivity }\end{array}$ & No & $\begin{array}{l}\text { Originally no, but can be enabled by } \\
\text { embedding the proposed control }\end{array}$ & Yes \\
\hline Steady State current rating & High: proportional to reactive power & High: proportional to reactive power & Zero \\
\hline
\end{tabular}

